\title{
The influence of estrogen on sex-related differences in pain perception using dog as an animal model
}

\author{
L. Miguel Carreira ${ }^{1,2,3 *}$ and Pedro Azevedo ${ }^{3}$ \\ ${ }^{1}$ Faculty of Veterinary Medicine, Department of Clinic - Surgery, University of Lisbon (FMV/ULisboa), Av. da Universidade Técnica de Lisboa, Polo Universitário \\ Alto da Ajuda, 1300-477 Lisbon, Portugal \\ ${ }^{2}$ Centre for Interdisciplinary Research in Animal Health (CIISA), FMV/ULisboa, Av. da Universidade Técnica de Lisboa, Polo Universitário Alto da Ajuda, 1300- \\ 477 Lisbon, Portugal \\ ${ }^{3}$ Anjos of Assis Veterinary Medicine Centre (CMVAA), Rua Da. Francisca da Azambuja No 9 - 9A; 2830-077 Barreiro, Portugal
}

\begin{abstract}
Objective: Evaluate the effects of the steroidal sexual hormone estrogen upon sex-related differences in pain perception within a scenario of perioperative orthopedics surgery, using the dog as an animal model.

Materials and methods: A sample of 60 dogs $(n=60)$ of both genders divided by three groups each with 20 individuals: neutered females (NF), non-neutered females (NNF), and males (ML) was used. These animals were regular hospital patients submitted to orthopaedic surgery (OTS), and were evaluated for their pain level using the Melbourne Pain Scale (MPS). The patients' pain level was evaluated over 3 peri-operative time points: M0 (immediately before surgery), M1 (24 hours after surgery) and M2 (8 days after surgery).

Results: Patients experienced lower pain levels across the time points, and this reduction was statistically significant between M0M1, M1M2 and M0M2, for the groups NF, NNF and ML ( $\mathrm{p}<0.001$ for all). Statistically significant differences in the final pain scores assessed with the MPS were found only between pair-wise NF/ ML at M0 (p=0.016) and M1 (p=0.042). Correlations between NNF and ML were strong at M0 (rho=0.81), M1 (rho=0.64), and M2 (rho=0.79).

Conclusions: The NF group can be representative of women with low estrogens concentration. The MPS used to rate pain levels was useful in identifying and grading the NF, NNF and ML groups' pain in patients during the peri-operative period, with males always presenting lower values than females. It is possible to conclude that steroid hormones, such as estrogens, influence sex-related differences in pain perception between females and males, with statistically significant differences registered between the NF and ML groups. Therefore, analgesic protocols developed by clinicians should always consider the gender and gonadal status of the patients.
\end{abstract}

\section{Introduction}

Since 2001, pain has been considered the fifth vital sign, which has led to research in different fields attempting to clarify pain's associated pathophysiological mechanisms [1-3]. Pain is a dynamic phenomenon influenced by several factors, including excitatory and inhibitory regulatory mechanisms, which have important consequences on individuals' responses to analgesics [4-6]. Several clinical studies carried out in different species such humans, dogs, and rodents have shown that gender influences pain stimulus modulation and pain perception, with substantial differences in pain perception between males and females [6-9]. In humans, women have lower pain thresholds than men, and women experience higher pain perception than men. These differences can be explained by various biological factors, such as the steroidal action of sexual hormones, which forms one of the main mechanisms that modulates variations in pain perception between genders $[6,10$ 14]. In the nervous system, steroid hormones, such as estrogen, induce many effects including modulation of neurotransmitters in the brain, spinal cord and peripheral nerves, alteration of the excitability of specific regions of the brain, and influence available receptors for themselves and other ligands, such as opiates and serotonin, which are expressed in various parts of the nociceptive pathway [15-19]. These effects could impact pain perception. An individual's inability to communicate pain does not mean that an individual cannot experience pain, thus requiring pain therapy [14]. Pain is a transversal issue that requires study under a zooubiquity scenario in both animal and human patients, since the inability to verbally express pain is not exclusive to animals but also applies to human infants, nonverbal, comatose, and cognitively impaired patients [20-23]. In veterinary medicine, patients express pain in different ways. The difficulty of assessing and quantifying pain is an important topic associated with species, age and breed-related differences, and the subjectivity and variability related to pain scales may result in the failure or success of determining patients' therapeutic levels [24-27]. The development of multidimensional, or composite, pain scales considering physiological and behaviour characteristics and variations, such as the Melbourne Pain Scale (MPS), was significant, due to its ability to evaluate dogs' pain in a multi-dimensional fashion [28,29]. The Melbourne Pain Scale (MPS) delivers one example. MPS is based on the assessment of six categories, which includes objective physiological measurements, such

Correspondence to: L. Miguel Carreira, Department of Clinics - Surgery, Faculty of Veterinary Medicine, University of Lisbon (FMV-ULisboa), Av. da Universidade Técnica de Lisboa, Polo Universitário Alto da Ajuda, 1300-477 Lisbon, Portugal, Tel: +351213652893; E-mail: miguelcarreira@fmv.ulisboa.pt

Key words: dog, pain, gender, sex hormones, estrogen, pain scale

Received: May 29, 2016; Accepted: June 24, 2016; Published: June 27, 2016 
as heart and respiratory rates, response to intervened tissues palpation, activity, posture, mental status and vocalization [30,31]. By translating a subjective assessment of pain into an objective score with recognized clinical relevance, it is possible to obtain useful, reliable, nonbiased, and repeatable data, reducing the variability between clinicians [32]. This study evaluated the effects of the steroidal sexual hormone estrogen upon sex-related differences in pain perception within a scenario of perioperative orthopedics surgery, using the dog as an animal model.

\section{Materials and methods}

The study used a sample of 60 dogs $(n=60)$ of both genders divided by three groups each with 20 individuals: neutered females (NF), nonneutered females (NNF), and males (ML). These animals were regular hospital patients, that underwent orthopaedic surgery (OTS) to correct the presence of fractures, and at no time were these animals used as experimental animals. The owners of the patients signed a consent form for participation. The patients' pain level was evaluated using the Melbourne Pain Scale (MPS) over 3 peri-operative time points: M0 (immediately before surgery), M1 (24 hours after surgery) and M2 (8 days after surgery). MPS allow us to evaluating physiological and behavioural parameters for each patient; scoring from 0 to 27 . Patients' pain score were always evaluated by the same two researchers, and in order to not influence the results, the observers were blind to information regarding the gender and gonadal status of the animal and the type of osteosynthesis each patient undergone. At the end, the mean of obtained values for final pain score of each patient was used to the statistical analysis. By assuming that individuals vary in their experience and expression of pain, and considering that different breeds typically present different responses to pain-where small breeds are generally more reactive than large breeds [33], and some breeds tend to be more stoic than others (for example, Poodle versus Rottweiler) [32,34]. We evenly distributed the different breeds between the females and males, to achieve more uniform results when we looked at pain level versus gender. All patients were submitted to continuous intravenous (IV) administration of physiological saline $\left(5 \mathrm{ml} \mathrm{kg} \mathrm{hour}^{-1}\right)$, and to the same anaesthesia and analgesia protocols, which consisted in carprofen $(4 \mathrm{mg}$ $\left.\mathrm{kg}^{-1}\right)$; diazepam $\left(0.1 \mathrm{mg} \mathrm{kg}^{-1}\right)$; metadone $\left(0.5 \mathrm{mg} \mathrm{kg}^{-1}\right)$ prior to surgery. Also a patch of fentanilo was used for each patient prior to surgery. Anaesthesia was induced with propofol $1 \%\left(4-6 \mathrm{mg} \mathrm{kg}^{-1}\right)$ and maintained with isoflurane. Patients presenting high scores of pain immediately after surgery were submitted to a rescue protocol with buprenorphine $\left(0.02 \mathrm{mg} \mathrm{kg}^{-1}\right)$ in order to achieve a comfort state. Buprenorphine is a synthetic opiate, used for the management of moderate pain, rapidly absorbed after injection and the effects are usually felt within 15 to 30 minutes, lasting about 6 hours [35]. Considering that rescue protocol could have affected the pain evaluation, we decided to consider the time point M1 as 24 hours after surgery, to ensure that the patients were no longer under bupernorphine action and use this data for statistical analysis. During the post-operative period the following drugs were used: cefixime (10 $\left.\mathrm{mg} \mathrm{Kg}^{-1}\right)$ BID, carprofen $\left(4 \mathrm{mg} \mathrm{kg}^{-1}\right)$ SID. In order to reduce bias variations and to standardize the results, the following inclusion criteria were used for all patients in the study: ages between 3 and 7 years old, and each patient presented only one long bone fracture which was corrected with the use of dynamic compression plates (DCP) and screws. All surgeries were performed by the same surgeon. For statistical analysis, we used SPSS software version 11.1. The two-tailed $\mathrm{t}$-test was performed. The nonparametric tests, Spearman correlation coefficient was used to evaluate the correlation between variables, and the Mann-Whitney test was used to analyze the medians variance in the sample. The results were considered statistically significant at a $\mathrm{p}$ value $<0.05$.

\section{Results}

The sample's age, body weight, breeds, type and duration of surgical procedure, and MPS scores (M0, M1, M2) are listed in Table 1. Average values obtained for pain levels with MPS in neutered females were $11.65 \pm 4.46$ in M0, $4.06 \pm 2.10$ in M1 and $1.41 \pm 1.04$ in M2; in non-neutered females were $9.51 \pm 3.59$ in M0, $3.44 \pm 1.52$ in $\mathrm{M} 1$ and $1.00 \pm 0.75$ in M2; and in males were $8.89 \pm 3.56$ in M0, $2.93 \pm 1.16$ in M1 and $0.89 \pm 0.72$ in M2. The two-tailed test showed that patients experienced lower pain levels across the time points, and this reduction was statistically significant between M0M1, M1M2 and M0M2, for the three considered groups NF, NNF and ML $(p<0.001$ for all). Statistically significant differences in the final pain scores assessed with the MPS were found only between pair-wise NF/ML at M0 ( $p=0.016)$ and M1 $(p=0.042)$. The Spearman coefficient test showed low correlations between NF and NNF at M0 (rho= - 0.17$)$, M1 (rho=$0.07)$, and $\mathrm{M} 2(\mathrm{rho}=0.14)$. The same was registered between NF and $\mathrm{ML}$ at M0 (rho=-0.03), M1 (rho=-0.04), and M2 (rho=0.18). Contrary, correlations between NNF and ML were strong at M0 (rho=0.81), M1 (rho=0.64), and M2 (rho=0.79).

\section{Discussion}

The aim of the study was to evaluate the influence of the steroidal hormone estrogen in modulating sex-related differences in pain perception within a scenario of perioperative orthopedics surgery, using the dog as an animal model. Individuals of both genders (females and males) were similar regarding age, body weight, breed and surgery parameters. Surgery type and duration presented a very similar distribution between both genders, without statistically significant differences between females and males $(p=0.857)$.

Identical nociceptive stimuli, applied under similar environmental conditions, promoted a highly-variable pain response across individuals, since pain is more than an objectively quantifiable physiological response: it is an experience [28]. Methods for assessing pain-perception or intensity-in animals is challenging, and still remains subjective due to its observational nature; therefore, it presented some limitations [28,30,33,36,37]. Subjective evaluation through observation and animal variation behaviors are commonly used for pain assessment, making difficult to obtain reliable, repeatable, useful, and nonbiased data [36-41]. Ideally, a subjective scoring scale correlates to objective measurements with a well-established clinical relevance [32]. In an effort to provide reliable pain evaluation scales, several pain scales have been developed, integrating behavioral and physiological observations that can be scored. Differences between pre- and post-operative physiological values were presumed to be indicators of patient pain intensity [42]. However, variations in these physiological data have not yet been established as true pain severity indicators in animals [43-47]. Pre-emptive pain surgical rating is important before conducting surgical procedures, to allow surgeons to develop analgesic protocols suitable to each patient's clinical condition and to ensure comfort for the patient by controlling the expected pain level resulting from the surgery [29].

Another factor to consider is an individual's response to opioid analgesics, which appears to vary with the patient's gender. Some studies concluded that different responses to opioid analgesics between genders are modulated mainly by G-protein $[7,48]$. The endogenous $\mu$-opioid neurotransmitters are related to stress and pain suppression. In animals, opioids tend to demonstrate more effective action in males than in females [49-51]. This is in line with the results of this study, where although all patients underwent the same post-operative, 
Table 1. Characterisation of the sample according to age, body weight, breed and type of surgical procedure. Also the final scores using the MPS at M0, M1 and M2.

\begin{tabular}{|c|c|c|c|c|c|c|c|c|c|}
\hline \multicolumn{6}{|c|}{ Parameter } & $\mathbf{N}$ & Mean & SD & $\mathbf{N}$ \\
\hline \multirow{4}{*}{\multicolumn{6}{|c|}{ Age (years) }} & Total & 60 & 5.12 & 1.46 \\
\hline & & & & & & NF & 20 & 5.28 & 1.47 \\
\hline & & & & & & NNF & 20 & 5.20 & 1.52 \\
\hline & & & & & & ML & 20 & 4.93 & 1.49 \\
\hline \multirow{4}{*}{\multicolumn{6}{|c|}{ Weight (Kg) }} & Total & 20 & 12.54 & 3.92 \\
\hline & & & & & & NF & 20 & 12.07 & 4.11 \\
\hline & & & & & & NNF & 20 & 12.48 & 3.90 \\
\hline & & & & & & ML & 20 & 13.13 & 3.75 \\
\hline \multirow{4}{*}{\multicolumn{6}{|c|}{ Surgery duration (minutes) }} & Total & 60 & 63.24 & 22.24 \\
\hline & & & & & & NF & 20 & 62.37 & 21.94 \\
\hline & & & & & & NNF & 20 & 64.02 & 20.89 \\
\hline & & & & & & ML & 20 & 64.30 & 23.23 \\
\hline \multicolumn{7}{|c|}{ Breed } & Sample & Females & Males \\
\hline \multicolumn{7}{|c|}{ Crossbreed } & 35 & 17 & 18 \\
\hline \multicolumn{7}{|c|}{ Poodle } & 8 & 3 & 5 \\
\hline \multicolumn{7}{|c|}{ Boxer } & 6 & 3 & 3 \\
\hline \multicolumn{7}{|c|}{ Rottweiller } & 3 & 2 & 1 \\
\hline \multicolumn{7}{|c|}{ Pit-bull } & 4 & 1 & 3 \\
\hline \multicolumn{7}{|c|}{ French Bulldogue } & 4 & 2 & 2 \\
\hline \multicolumn{6}{|c|}{ Surgical procedure } & Sample & Neutered Females (NF) & $\begin{array}{c}\text { Non-Neutered Females } \\
\text { (NNF) }\end{array}$ & Males (ML) \\
\hline \multicolumn{6}{|c|}{ Diaphyseal fracture of the femur } & 23 & 6 & 4 & 13 \\
\hline \multicolumn{6}{|c|}{ Proximal epiphyseal fracture of the femur } & 5 & 1 & 1 & 3 \\
\hline \multicolumn{6}{|c|}{ Distal epiphyseal fracture of the femur } & 8 & 3 & 2 & 3 \\
\hline \multicolumn{6}{|c|}{ Diaphyseal fracture of the tibia } & 9 & 2 & 2 & 5 \\
\hline \multicolumn{6}{|c|}{ Proximal epiphyseal fracture of the tibia } & 4 & 1 & 1 & 2 \\
\hline \multicolumn{6}{|c|}{ Distal epiphyseal fracture of the tibia } & 5 & 1 & 1 & 3 \\
\hline \multicolumn{6}{|c|}{ Diaphyseal fracture of the humerus } & 4 & 1 & 2 & 1 \\
\hline \multicolumn{6}{|c|}{ Proximal epiphyseal fracture of the humerus } & 2 & 0 & 1 & 1 \\
\hline \multicolumn{10}{|c|}{ MPS Score } \\
\hline & \multicolumn{3}{|c|}{ Neutered Females (NF) } & \multicolumn{3}{|c|}{ Non-Neutered Females (NNF) } & \multicolumn{3}{|c|}{ Males (ML) } \\
\hline & Mo & M1 & M2 & Mo & M1 & M2 & Mo & M1 & M2 \\
\hline $\bar{x}$ & 11.65 & 4.06 & 1.41 & 9.51 & 3.44 & 1.0 & 8.89 & 2.93 & 0.89 \\
\hline SD & 4.06 & 2.10 & 1.04 & 3.59 & 1.52 & 0.75 & 3.56 & 1.16 & 0.72 \\
\hline $\min$ & 5.0 & 1.0 & 0.0 & 3.0 & 1.0 & 0.0 & 3.0 & 1.0 & 0.0 \\
\hline $\max$ & 19.0 & 9.0 & 6.0 & 18.0 & 7.0 & 2.0 & 18.0 & 5.0 & 2.0 \\
\hline
\end{tabular}

Sample (N): Standart deviation (SD);Kilogram (Kg); Mean ( $\bar{x}$ ); Melbourne pain scale (MPS); Moment immediately after surgery (M0); Moment 24 hours after surgery (M1), Moment 8 days after surgery (M2); Orthopedics surgery OSTS

multimodal analgesic protocol that proved to be suitable for nearly all the patients submitted to surgery, the overall response in males was better than in females. Therefore, females provided a lower score over the post-surgery time points considered in the study. In addition, the number of females (7) submitted to the rescue analgesic protocol with buprenorphine, to achieve a comfortable state, was higher than the number of males (4). Females represented $63 \%$ of the group where the rescue analgesic protocol was used. Among the female patients, five were NF and only two were NNF. Previous studies on the nociceptive pain and inflammatory model assessed differences in the perception of pain between genders [12]. In humans, studies suggest that women have lower pain thresholds than men: therefore women have higher perceptions of pain than males, which can be explained by the steroidal action of sexual hormones, such as estrogen [6,10-13,24].

Many of the central regions involved in pain and analgesia, specifically the periaqueductal grey, bone marrow, and dorsal root ganglia, contain receptors for estrogens, and can synthesise them locally, particularly in the hippocampus by using endogenous cholesterol [18,55-59]. By binding to specific receptors in tissues, sexual hormones initiate, terminate, or amplify a transcription signal, affecting the transcriptional events that influence the expression of various neurotransmitters and receptors, which are then translated into a functional clinical significance $[52,53,60]$. Sexual hormones act as neuroactive steroids, affecting the nervous system dynamics and brain functions via neurotransmission modulation $[61,62]$, by controlling neuronal excitability through specific interactions with neurotransmitter receptors (genomic action) and ion channels (nongenomic action) $[8,63,64]$. Glutamate, $\gamma$-Aminobutyric acid (GABA), and acetylcholine (ACh) are first-generation neuromessengers, which are stored in pre-synaptic vesicles and can be quickly released. In contrast, the neuroactive steroids-produced in the mitochondrias and microsomes of neurons and glial cells-are slowly released via passive diffusion [56]. Changes in serum estrogen concentrations are accompanied by changes in a variety of other neurotransmitters, such as serotonin, ACh, dopamine, and $\beta$-endorphins. Their reduction accompanies decreases in serum estrogen concentrations $[54,65]$. Since estrogen has significant anti-nociceptive actions, lower estrogen levels are associated with increased pain and with impairment of descending 
Table 2. Correlation between neutered females (NF), Non-neutered females (NNF) and males (ML) for the Melbourne Pain Scale (MPS) score at time points M0, M1, and M2. Comparation of the mean between both genders.

\begin{tabular}{|c|c|c|c|c|c|}
\hline $\begin{array}{l}\text { Parameter/ } \\
\text { Time point }\end{array}$ & $\mathbf{N}$ & Comparation pairs & Spearman (rho) & $\begin{array}{l}\text { Two-tailed test } \\
\text { p-value }\end{array}$ & $\begin{array}{c}\text { Mann-Whitney test } \\
\text { p-value }\end{array}$ \\
\hline \multirow{2}{*}{ Surgery duration } & 40 & ML vs. NF & -0.36 & 0.221 & 0.857 \\
\hline & 40 & ML vs. NNF & -0.31 & 0.187 & 0.813 \\
\hline Mo & \multirow{3}{*}{40} & NF $v s$. NNF & -0.17 & 0.351 & 0.06 \\
\hline M1 & & NF $v s . \mathrm{NNF}$ & -0.07 & 0.715 & 0.327 \\
\hline M2 & & NF $v s . \mathrm{NNF}$ & 0.14 & 0.441 & 0.438 \\
\hline Mo & \multirow{3}{*}{40} & ML vs. NF & -0.03 & 0.841 & $0.016 *$ \\
\hline M1 & & ML vs. NF & -0.04 & 0.820 & $0.042 *$ \\
\hline M2 & & ML $v s . \mathrm{NF}$ & 0.186 & 0.298 & 0.219 \\
\hline Mo & \multirow{3}{*}{40} & ML vs. NNF & 0.816 & $<0.01$ & 0.502 \\
\hline M1 & & ML vs. NNF & 0.649 & $<0.01$ & 0.222 \\
\hline M2 & & ML vs. NNF & 0.790 & $<0.01$ & 0.603 \\
\hline
\end{tabular}

Sample (N); Moment 48 hours ater surgery (M2); Moment 24 hours ater surgery (M1); Moment 8 days after surgery (M2). ML (males); NF (Neutered Females); NNF (Non-neutered females). * statistically significant

pain inhibitory pathways $[18,19,43]$.

By using a NF group in our study, we can evaluate what is happening in women with low estrogens concentration, as occurring in hysterectomy or with the onset of menopause, and try to understand if estrogen levels played a major role in differences of pain perception, by comparing the final MPS scores in the NF and NNF groups with the ML group. NFs presented lower estrogens levels than NNFs; thus, we expected that differences in pain perception would be more marked between the NF/ML pair-group, than in the NNF/ML pairgroup. According to the results, the evolution of pain experienced by patients, evaluated at the three times considered, showed the same trend for all three groups (NF, NNF, ML), suggesting that post-surgery pain levels decreased consistently over time. According to the results, females showed higher final pain scores using the MPS at all time points (M0, M1, M2), than did males. At the end of the study (M2), the average scores obtained were 1.41 for the NF group, 1.00 for the NNF group, and 0.89 for the ML group, which demonstrated overall good pain control, considering that the maximum MPS score is 27. No significant differences for the final pain score were registered between the NF and NNF groups $(p=0.06)$. Nevertheless, this $p$-value is very close to a significant result of $p<0.05$, suggesting that a larger sample size might have achieved a significant difference between these groups. Statistically significant differences in pain level scores were registered between the NF and ML groups at M0 ( $p=0.016)$, and at M1 ( $p=0.042)$, with greatly improved patients' comfort occurring within the first 24 hours after surgery. Comparisons between the NNF and ML groups presented no statistically significant differences at any time point (M0, M1, M2).

\section{Conclusion}

Human and animals pain perception is influenced by several biological variables. The MPS used to rate pain levels was useful in identifying and grading the NF, NNF and ML groups' pain in patients during the peri-operative period, with males always presenting lower values than females. It is possible to conclude that steroid hormones, such as estrogens, influence sex-related differences in pain perception between females and males, with statistically significant differences registered between the NF and ML groups. Therefore, analgesic protocols developed by clinicians should always consider the gender and gonadal status of the patients.

\section{Acknowledgments}

The authors thank to Centre for Interdisciplinary of Research in
Animal Health - CIISA, of Faculty of Veterinary Medicine of Lisbon, of the University of Lisbon (FMV/Ulisboa)-Portugal; to Anjos of Assis Veterinary Medicine Centre (CMVAA), Barreiro - Portugal.

\section{References}

1. Hellyer P, Rodan I, Brunt J, Downing R, Hagedorn JE, Robertson SA (2007) AHA AAFP pain management guidelines for dogs and cats. J Feline Med Surg 9: 466-480.

2. Rollin BE (2008) The ethics of pain management. In: Handbook of veterinary pain management. Gaynor JS, Muir WW (eds). St Louis, Mosby 2-11.

3. Dyson DH (2008) Perioperative pain management in veterinary patients. Vet Clin North Am Small Anim Pract 38: 1309-1327. [Crossref]

4. Mira F, Costa A, Mendes E, Azevedo P, Carreira LM (2015) A pilot study exploring the effects of musical genres on the depth of general anaesthesia assessed by haemodynamic responses. J Feline Med Surg pii: 1098612X15588968. [Crossref]

5. Mira F, Costa A, Mendes E, Azevedo P, Carreira LM (2015) Influence of music and its genres on respiratory rate and pupil diameter variations in cats under general anaesthesia: contribution to promoting patient safety. J Feline Med Surg 17: 645-648. [Crossref]

6. Palmeira CC, Ashmawi HA, Posso Ide P (2011) Sex and pain perception and analgesia Rev Bras Anestesiol 61: 814-828. [Crossref]

7. Wiesenfeld-Hallin Z (2005) Sex differences in pain perception. Gend Med 2: 137-145. [Crossref]

8. Aloisi AM, Ceccarelli I, Herdegen T (2000) Gonadectomy and persistent pain differently affect hippocampal c-Fos expression in male and female rats. Neurosci Lett 281: 29-32. [Crossref]

9. Hurley RW, Adams MC (2008) Sex, gender, and pain: an overview of a complex field Anesth Analg 107: 309-317. [Crossref]

10. Berkley KJ (1997) Sex differences in pain. Behav Brain Sci 20: 371-380. [Crossref]

11. Fillingim RB, Gear RW (2004) Sex differences in opioid analgesia: clinical and experimental findings. Eur J Pain 8: 413-425. [Crossref]

12. Gaumond I, Arsenault P, Marchand S (2005) Specificity of female and male sex hormones on excitatory and inhibitory phases of formalin-induced nociceptive responses. Brain Res 1052: 105-111. [Crossref]

13. Thompson AD, Angelotti T, Nag S, Mokha SS (2008) Sex-specific modulation of spinal nociception by alpha-adrenoceptors: differential regulation by estrogen and testosterone. Neuroscience 153: 1268-1277. [Crossref]

14. Benedito-Castellote S (1995) Fisiología del Nervio. In: Fisiologia Veterinaria. GarciaSancristán A, Castejón F,CruzPalomino LF, González-Gallego J, López de Silanes MdM, Salido Ruiz G, (eds). Madrid: McGraw-Hill 11-40.

15. Craft RM (2007) Modulation of pain by estrogens. Pain 132 Suppl 1: S3-S12. [Crossref]

16. Aloisi AM, Bonifazi M (2006) Sex hormones, central nervous system and pain. Horm Behav 50: 1-7. [Crossref]

17. Smith YR, Stohler CS, Nichols TE, Bueller JA, Koeppe RA, Zubieta JK (2006) Pronociceptive and antinociceptive effects of estradiol through endogenous opioid 
neurotransmission in women. $J$ Neurosci 26: 5777-5785. [Crossref]

18. Vincent K, Tracey I (2008) Hormones and their interaction with the pain experience. Rev Pain 2: 20-24. [Crossref]

19. Sarajari S, Oblinger MM (2010) Estrogen effects on pain sensitivity and neuropeptide expression in rat sensory neurons. Exp Neurol 224: 163-169. [Crossref]

20. Chang PC, Yeh CH (2005) Agreement between child self-report and parent proxyreport to evaluate quality of life in children with cancer. Psychooncology 14: 125-134. [Crossref]

21. Loewenstein DA, Arguelles S, Bravo M, Freeman RQ, Arguelles T, Acevedo A, et al. (2001) Caregivers' judgments of the functional abilities of the Alzheimer's disease patient: a comparison of proxy reports and objective measures. J Gerontol B Psychol Sci Soc Sci 56: 78-84. [Crossref]

22. Schnakers C, Chatelle C, Vanhaudenhuyse A, Majerus S, Ledoux D, et al. (2010) The Nociception Coma Scale: a new tool to assess nociception in disorders of consciousness. Pain 148: 215-219. [Crossref]

23. Fuchs-Lacelle S, Hadjistavropoulos T (2004) Development and preliminary validation of the pain assessment checklist for seniors with limited ability to communicate (PACSLAC). Pain Manag Nurs 5: 37-49. [Crossref]

24. Molony V, Kent JE (1997) Assessment of acute pain in farm animals using behavioral and physiological measurements. J Anim Sci 75: 266-272. [Crossref]

25. Schnitzler A, Ploner M (2000) Neurophysiology and functional neuroanatomy of pain perception. J Clin Neurophysiol 17: 592-603. [Crossref]

26. VMA (2001) adopts position regarding animal pain. J Am Vet Med Assoc 218:1694.

27. American Animal Hospital Association; American Association of Feline Practitioners; AAHA/AAFP Pain Management Guidelines Task Force Members, Hellyer P, Rodan I, Brunt J, et al. (2007) AAHA/AAFP pain management guidelines for dogs and cats. $J$ Amer Anim Hosp Assoc. 43: 235-248. [Crossref]

28. Hansen BD (2003) Assessment of pain in dogs: veterinary clinical studies. ILAR J 44: 197-205. [Crossref]

29. Mich PM, Hellyer PW (2008) Objective, Categoric Methods for Assessing Pain and Analgesia. In: Handbook of veterinary pain management. Gaynor JS, Muir WW (eds). St Louis: Mosby. $78-107$

30. Sharkey M (2013) The challenges of assessing osteoarthritis and postoperative pain in dogs. AAPS J 15: 598-607. [Crossref]

31. Firth AM, Haldane SL (1999) Development of a scale to evaluate postoperative pain in dogs. J Am Vet Med Assoc 214: 651-659. [Crossref]

32. Connolly G (2000) Companion animal analgesics: Assessment of pain.

33. National Academies Press (US) (2009) NRC - National Research Council (US) Committee on Recognition and Alleviation of Pain in Laboratory Animals. Recognition and Alleviation of Pain in Laboratory Animals. Washington (DC): Recognition and Assessment of Pain. [Crossref]

34. Dobromylskyij P, Flecknell PA, Lascelles BD, et al. (2000) Pain assessment. In: Flecknell PA, Waterman-Pearson A, et al., editors. Pain management in animals. London: Saunders 53-79. [Crossref]

35. Plumb DC (2015) Plumb's Veterinary Drug Handbook, $8^{\text {th }}$ ed. Wiley-Blackwell.

36. Rialland P, Authier S, Guillot M, Del Castillo JR, Veilleux-Lemieux D, et al. (2012) Validation of orthopedic postoperative pain assessment methods for dogs: a prospective, blinded, randomized, placebo-controlled study. Gilestro GF, ed. PLOS ONE 7: e49480. [Crossref]

37. de Oliveira FA, Luna SP, do Amaral JB, Rodrigues KA, Sant'Anna AC, et al. (2014) Validation of the UNESP-Botucatu unidimensional composite pain scale for assessing postoperative pain in cattle. BMC Vet Res 10: 200. [Crossref]

38. Stallard P, Williams L, Velleman R, Lenton S, McGrath PJ, et al. (2002) The development and evaluation of the pain indicator for communicatively impaired children (PICIC). Pain 98: 145-149. [Crossref]

39. Wiseman ML, Nolan AM, Reid J, Scott EM (2001) Preliminary study on ownerreported behaviour changes associated with chronic pain in dogs. Vet Rec 149: 423424. [Crossref]

40. Hansen BD, Lascelles BD, Keene BW, Adams AK, Thomson AE (2007) Evaluation of an accelerometer for at-home monitoring of spontaneous activity in dogs. Am J Vet Res 68: 468-475. [Crossref]

41. Hielm-Björkman AK, Kuusela E, Liman A, Markkola A, Saarto E, et al. (2003)
Evaluation of methods for assessment of pain associated with chronic osteoarthritis in dogs. J Am Vet Med Assoc 222: 1552-1558. [Crossref]

42. Conzemius MG, Hill CM, Sammarco JL, Perkowski SZ (1997) Correlation between subjective and objective measures used to determine severity of postoperative pain in dogs. J Am Vet Med Assoc 210: 1619-1622. [Crossref]

43. Henry NL, Conlon A, Kidwell KM, Griffith K, Smerage JB, Schott AF, et al. (2014) Effect of estrogen depletion on pain sensitivity in aromatase inhibitor-treated women with early-stage breast cancer. J Pain 15: 468-475. [Crossref]

44. Holton LL, Scott EM, Nolan AM, Reid J, Welsh E (1998) Relationship between physiological factors and clinical pain in dogs scored using a numerical rating scale. $J$ Small Anim Pract 39: 469-474. [Crossref]

45. Gellasch KL, Kruse-Elliott KT, Osmond CS, Shih AN, Bjorling DE (2002) Comparison of transdermal administration of fentanyl versus intramuscular administration of butorphanol for analgesia after onychectomy in cats. J Am Vet Med Assoc 220: 1020 1024. [Crossref]

46. Drendel AL, Kelly BT, Ali S (2011) Pain assessment for children: overcoming challenges and optimizing care. Pediatr Emerg Care 27: 773-781. [Crossref]

47. Marco CA, Plewa MC, Buderer N, Hymel G, Cooper J (2006) Self-reported pain scores in the emergency department: lack association with vital signs. Acad Emerg Med 13 : 974-979. [Crossref]

48. Claiborne J, Nag S, Mokha SS (2006) Activation of opioid receptor like-1 receptor in the spinal cord produces sex-specific antinociception in the rat: estrogen attenuates antinociception in the female, whereas testosterone is required for the expression of antinociception in the male. J Neurosci 26: 13048-13053. [Crossref]

49. Zubieta JK, Smith YR, Bueller JA, Xu Y, Kilbourn MR, et al. (2002) mu-opioid receptor-mediated antinociceptive responses differ in men and women. $J$ Neurosci 22 5100-5107. [Crossref]

50. Cook CD, Barret AC, Roach AL, Bowman JR, Picker MJ (2000) Sex-related differences in the antinociceptive effects of opioids: importance of rat genotype, nociceptive stimulus intensity, and efficacy at the mu opioid receptor. Psychopharmacology 150 430-442. [Crossref]

51. Dahan A, Kest B, Waxman AR, Sarton E (2008) Sex-specific responses to opiates: animal and human studies. Anesth Analg 107: 83-95. [Crossref]

52. Brody S, Carlstrom K, Lagrelius A, Lunell NO, Möllerström G, Pousette A (1987) Serum sex hormone binding globulin (SHBG), testosterone/SHBG index, endometrial pathology and bone mineral density in postmenopausal women. Acta Obstet Gynecol Scand 66: 357-360. [Crossref]

53. Beyenburg S, Stoffel-Wagner B, Bauer J, Watzka M, Blümcke I, et al. (2001) Neuroactive steroids and seizure susceptibility. Epilepsy Res 44: 141-153. [Crossref]

54. Mellon SH (1994) Neurosteroids: biochemistry, modes of action, and clinical relevance. J Clin Endocrinol Metab 78: 1003-1008. [Crossref]

55. Shibuya K, Takata N, Hojo Y, Furukawa A, Yasumatsu N, et al. (2003) Hippocampa cytochrome $\mathrm{P} 450$ s synthesize brain neurosteroids which are paracrine neuromodulators of synaptic signal transdxuction. Biochim Biophys Acta 1619: 301-316. [Crossref]

56. Sinchak K, Mills RH, Tao L, LaPolt P, Lu JK, et al. (2003) Estrogen induces de novo progesterone synthesis in astrocytes. Dev Neurosci 25: 343-348. [Crossref]

57. Amateu SK, Alt JJ, Stamps CL, McCarthy MM (2004) Brain estradiol content in newborn rats: sex differences, regional heterogeneity, and possible de novo synthesis by the female telencephalon. Endocrinology 145: 2906-2917. [Crossref]

58. Evrard HC (2006) Estrogen synthesis in the spinal dorsal horn: a new central mechanism for the hormonal regulation of pain. Am J Physiol Regul Integr Comp Physiol 291: R291-R299. [Crossref]

59. Greenspan JD, Craft RM, LeResche L, Arendt-Nielsen L, Berkley KJ, et al. (2007) Studying sex and gender differences in pain and analgesia: a consensus report. Pain 132 Suppl 1: S26-45. [Crossref]

60. Murrell JC, Psatha EP, Scott EM, Reid J, Hellebrekers LJ (2008) Application of a modified form of the Glasgow pain scale in a veterinary teaching centre in the Netherlands. Vet Rec 162: 403-408. [Crossref]

61. Simpson ER (2003) Sources of estrogen and their importance. J Steroid Biochem Mol Biol 86: 225-230. [Crossref]

62. Robichaud M, Debonnel G (2005) Oestrogen and testosterone modulate the firing activity of dorsal raphe nucleus serotonergic neurones in both male and female rats. $J$ Neuroendocrinol 17: 179-185. [Crossref] 
Miguel Carreira L (2016) The influence of estrogen on sex-related differences in pain perception using dog as an animal model

63. Rupprecht R, Holsboer F (1999) Neuroactive steroids: mechanisms of action and neuropsychopharmacological perspectives. Trends Neurosci 22: 410-416. [Crossref]

64. Teyler TJ, Vardaris RM, Lewis D, Rawitch AB (1980) Gonadal steroids: effects on excitability of hippocampal pyramidal cells. Science 209: 1017-1018. [Crossref]
65. Rudick CN, Woolley CS (2000) Estradiol induces a phasic Fos response in the hippocampal CA1 and CA3 regions of adult female rats. Hippocampus 10: 274-283. [Crossref]

Copyright: (C2016 Miguel Carreira L. This is an open-access article distributed under the terms of the Creative Commons Attribution License, which permits unrestricted use, distribution, and reproduction in any medium, provided the original author and source are credited. 